\title{
A tandem approach for collocated measurements of microphysical and radiative cirrus properties
}

\author{
Marcus Klingebiel ${ }^{1,2}$, André Ehrlich ${ }^{3}$, Fanny Finger ${ }^{3}$, Timo Röschenthaler ${ }^{4,5}$, Suad Jakirlić ${ }^{5}$, Matthias Voigt ${ }^{6}$, \\ Stefan Müller ${ }^{4,6}$, Rolf Maser ${ }^{4}$, Manfred Wendisch ${ }^{3}$, Peter Hoor ${ }^{6}$, Peter Spichtinger ${ }^{6}$, and Stephan Borrmann²,6 \\ ${ }^{1}$ Max Planck Institute for Meteorology, Atmosphere in the Earth System Department, Hamburg, Germany \\ ${ }^{2}$ Max Planck Institute for Chemistry, Particle Chemistry Department, Mainz, Germany \\ ${ }^{3}$ Leipzig Institute for Meteorology (LIM), University of Leipzig, Leipzig, Germany \\ ${ }^{4}$ Enviscope GmbH, Frankfurt, Germany \\ ${ }^{5}$ Institute for Fluid Mechanics and Aerodynamics, Darmstadt University of Technology, Darmstadt, Germany \\ ${ }^{6}$ Institute for Atmospheric Physics, Johannes Gutenberg University Mainz, Mainz, Germany \\ Correspondence to: Stephan Borrmann (stephan.borrmann@mpic.de)
}

Received: 14 February 2017 - Discussion started: 5 April 2017

Revised: 14 July 2017 - Accepted: 4 August 2017 - Published: 22 September 2017

\begin{abstract}
Microphysical and radiation measurements were collected with the novel AIRcraft TOwed Sensor Shuttle (AIRTOSS) - Learjet tandem platform. The platform is a combination of an instrumented Learjet 35A research aircraft and an aerodynamic bird, which is detached from and retracted back to the aircraft during flight via a steel wire with a length of $4000 \mathrm{~m}$. Both platforms are equipped with radiative, cloud microphysical, trace gas, and meteorological instruments. The purpose of the development of this tandem set-up is to study the inhomogeneity of cirrus as well as other stratiform clouds. Sophisticated numerical flow simulations were conducted in order to optimally integrate an axially asymmetric Cloud Combination Probe (CCP) inside AIRTOSS. The tandem platform was applied during measurements at altitudes up to $36000 \mathrm{ft}(10970 \mathrm{~m})$ in the framework of the AIRTOSS - Inhomogeneous Cirrus Experiment (AIRTOSS-ICE). Ten flights were performed above the North Sea and Baltic Sea to probe frontal and in situ formed cirrus, as well as anvil outflow cirrus. For one flight, cirrus microphysical and radiative properties displayed significant inhomogeneities resolved by both measurement platforms. The CCP data show that the maximum of the observed particle number size distributions shifts with decreasing altitude from 30 to $300 \mu \mathrm{m}$, which is typical for frontal, midlatitude cirrus. Theoretical considerations imply that cloud particle aggregation inside the studied cirrus is very unlikely. Consequently, diffusional growth was identified to be the
\end{abstract}

dominant microphysical growth process. Measurements of solar downward and upward irradiances at $670 \mathrm{~nm}$ wavelength were conducted above, below, and in the cirrus on both the Learjet and AIRTOSS. The observed variability of the downward irradiance below the cirrus reflects the horizontal heterogeneity of the observed thin cirrus. Vertically resolved solar heating rates were derived by either using singleplatform measurements at different altitudes or by making use of the collocated irradiance measurements at different altitudes of the tandem platform. Due to unavoidable biases of the measurements between the individual flight legs, the single-platform approach failed to provide a realistic solar heating rate profile, while the uncertainties of the tandem approach are reduced. Here, the solar heating rates range up to $6 \mathrm{~K} \mathrm{day}^{-1}$ at top of the cirrus layer.

\section{Introduction}

Cirrus clouds consist of ice particles and occur in the upper troposphere and lower stratosphere at temperatures below $-38^{\circ} \mathrm{C}$ (IPCC, 2013; Koop et al., 2000). Their wide range of microphysical and macrophysical properties affects the solar and terrestrial radiative budget of the Earth's climate system. Depending on the microphysical properties cirrus either warms or cools the layer below the clouds (Lynch, 2002; Zhang et al., 1999). Among other factors, the ice parti- 
cle shape determines the cirrus radiative properties such as its albedo or spectral radiative layer properties (e.g. Wendisch et al., 2005, 2007; Eichler et al., 2009 or Finger et al., 2016). Ice particle shape and surface roughness may also cause biases in retrievals of cirrus properties from satellite measurements.

To quantify the dependence of the cloud radiative forcing from cloud properties, vertically separated observations of the cirrus microphysical and radiative properties are needed. This can be realized by consecutive measurements by one single aircraft or collocated observations by two platforms. The first approach is problematic due to the (usually too large) temporal displacement between the observations in, below, and above the cloud. Collocated measurements using two coordinated aircraft were attempted, for example during the Cirrus Regional Study of Tropical Anvils and Cirrus Layers - Florida Area Cirrus Experiment (CRYSTAL-FACE) in 2002 (Jensen et al., 2004), the Tropical Composition, Cloud and Climate Coupling (TC4) mission in 2007 (Toon, 2007), and the Radiation-Aerosol-Cloud Experiment in the Arctic Circle (RACEPAC) in 2014 (Ehrlich and Wendisch, 2015). However, as pointed out by Frey et al. (2009) and others, the exact vertical collocation between the two aircraft with different speeds is problematic as well. To minimize these collocation issues, towed sensor systems have been applied in the past.

During the CARRIBA (Cloud, Aerosol, Radiation and tuRbulence in the trade wInd regime over BArbados) project (Siebert et al., 2013) two platforms connected by a cable to a helicopter were applied to obtain collocated measurements of thermodynamic, turbulent, microphysical, and radiative properties within clouds. Werner et al. (2014) showed that such observations can be used to link cloud microphysical and radiative properties and estimate the Twomey effect in shallow cumulus. However, such helicopter measurements are limited to altitudes below $3000 \mathrm{~m}$ and therefore are not suited for investigating cirrus.

Frey et al. (2009) introduced a new tandem measurement platform consisting of a Learjet $35 \mathrm{~A}$ research aircraft and an AIRcraft TOwed Sensor Shuttle (AIRTOSS), which can operate in higher altitudes and velocities $\left(\sim 700 \mathrm{~km} \mathrm{~h}^{-1}\right)$. AIRTOSS is a sensor pod that is attached under the right wing of the Learjet. When the Learjet reaches the measurement area, AIRTOSS is released and towed by the aircraft via a steel wire. In 2007 a proof-of-concept campaign was conducted to evaluate the technical feasibility, the flight safety, and the flight performance of AIRTOSS. In the study of Frey et al. (2009), AIRTOSS was equipped with a Cloud Imaging Probe (CIP) to measure the microphysical properties of the clouds and two navigation systems. At this time, the configuration of the tandem platform was certified only to fly up to an altitude of $25000 \mathrm{ft}(7620 \mathrm{~m})$, which is below the altitude where most cirrus typically occurs. Frey et al. (2009) show that turbulence as well as acceleration and deceleration manoeuvres should be avoided to keep roll and pitch angles in a range of $\pm 3^{\circ}$, which appears tolerable for irradiance measurements (by definition related to a strictly horizontal receiving plane).

In this paper an advanced AIRTOSS platform including radiative and cloud microphysical instruments is introduced, which is certified for higher altitudes up to $41000 \mathrm{ft}$ $(12500 \mathrm{~m})$. Technical details of the redesigned AIRTOSS are presented in Sect. 2. Section 3 shows results of collocated measurements in cirrus clouds with the Learjet 35A and AIRTOSS. Two examples of collocated observations are discussed in Sect. 4. Section 5 summarizes the outcome and gives an overview of the strengths and weaknesses of the improved AIRTOSS-Learjet tandem platform.

\section{Technical development and properties of the AIRTOSS-Learjet tandem platform}

The advanced AIRTOSS-Learjet tandem platform includes radiation sensors and a sophisticated probe for cloud microphysical measurements. This set-up (see Fig. 1) was used during the AIRTOSS-Inhomogeneous Cirrus Experiment (AIRTOSS-ICE) in spring and autumn 2013 above the North Sea and Baltic Sea.

Ten flights, five in spring (6-8 May 2013) and five in autumn (29 August-5 September 2013), were performed during the AIRTOSS-ICE campaign. The release of AIRTOSS was only possible under strict safety regulations, and for this reason the measurement flights were only performed in restricted military areas. In order to reach cirrus altitudes a full formal aeronautical and aircraft certification had to be completed. After this complex procedure the tandem platform consisting of the Learjet 35A and the AIRTOSS was allowed to operate at altitudes up to $41000 \mathrm{ft}(12500 \mathrm{~m})$.

\subsection{The Learjet 35A research aircraft}

In this study a Learjet $35 \mathrm{~A}$ is applied (see Fig. 1a). It can reach a maximum flight distance of $1700 \mathrm{NM}(3148 \mathrm{~km})$ and a maximum altitude of $45000 \mathrm{ft}(13.7 \mathrm{~km})$ and typically cruises at speeds between 600 and $800 \mathrm{~km} \mathrm{~h}^{-1}$. The aircraft is equipped with a sensor pod mounted under the left wing (see Fig. 1b) and a winch for AIRTOSS under the right wing. This additional freight limits the maximum altitude (to $\sim 36000 \mathrm{ft}, 10970 \mathrm{~m}$ ) and endurance. Radiative, meteorological, and microphysical instruments are mounted inside AIRTOSS as well as on the fuselage of the aircraft.

\subsection{AIRcraft TOwed Sensor Shuttle (AIRTOSS)}

The original bird structure of AIRTOSS belongs to the shuttle case of the type DO-SK6 and is manufactured by the European Aeronautic Defence and Space Company (EADS). Primarily it is used as a flight target for military training. The original case and the inner frame structure were modified for implementing scientific instruments to perform measurements for atmospheric research. 

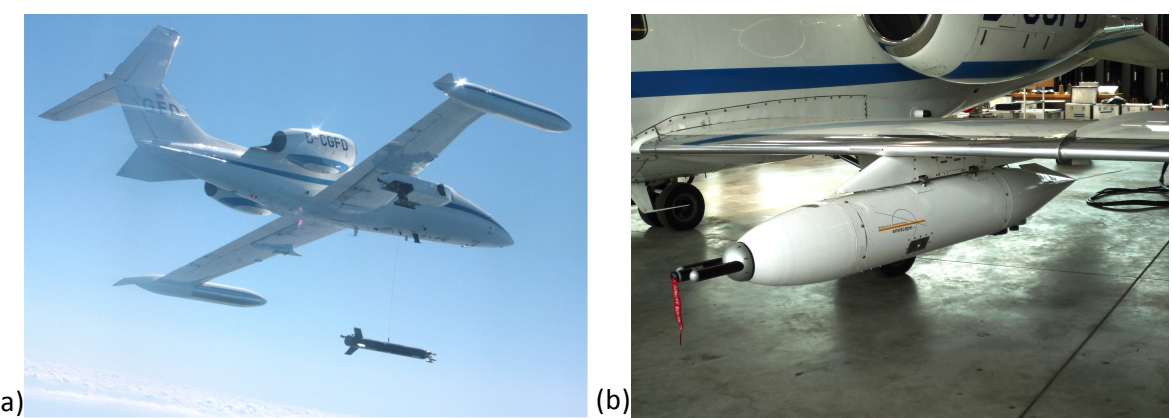

Figure 1. (a) Advanced AIRTOSS-Learjet tandem platform: Learjet 35A with the sensor shuttle (called AIRTOSS) during a test flight. The photograph was taken during the release of AIRTOSS. When AIRTOSS is fully released, the distance between the Learjet and AIRTOSS is $3000 \mathrm{ft}(914 \mathrm{~m})$. (b) Attached sensor pod under the left wing of the Learjet with the mounted FSSP at the tip.

(a)

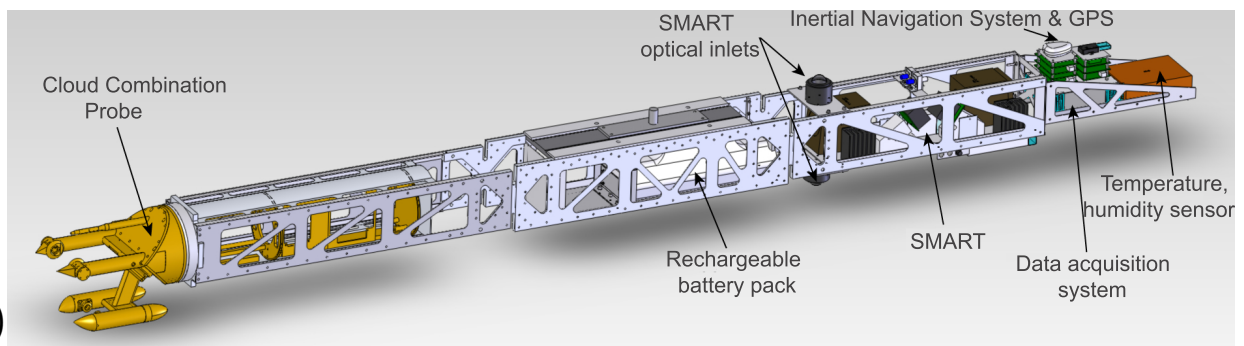

(b)

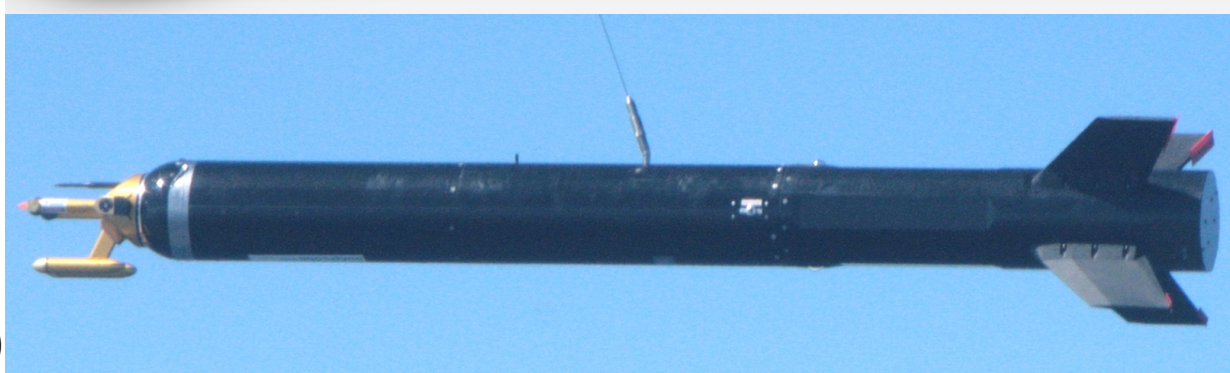

Figure 2. Different states of the AIRTOSS development process. Panel (a) shows a perspective view of the position of the instruments (Röschenthaler, 2013), including the Spectral Modular Airborne Radiation measurement sysTem (SMART). Panel (b) shows the manufactured AIRTOSS during a mission.

\subsubsection{Specifications}

A perspective view of the structure of AIRTOSS is shown in Fig. 2a. The internal frame consists of high-strength aviation aluminium EN AW-7075 and is separated into three sections. Structural elements on the internal frame allow all sensors to be mounted inside AIRTOSS, which has a length of $2.89 \mathrm{~m}$ and a diameter of $0.24 \mathrm{~m}$. The middle section includes the eyelet, which connects the AIRTOSS to the Learjet by a steel wire without electrical leads. A Cloud Combination Probe (CCP) is located in the front section, and the rear part of AIRTOSS contains mainly the radiation instruments. The original version used the external body cover (made of glass-fibre reinforced plastic) as a mounting point for additional payload. For the modified version, the body cover is used only as a cover, which does not need a detailed strength calculation and certification. It also makes it more convenient to access the instruments and to recharge the replaceable battery after a measurement flight.

The photograph in Fig. $2 \mathrm{~b}$ was taken from an accompanying second aircraft during a test flight for the Airworthiness Certification procedure. Air brakes (red rectangles at the winglets) with different resistance coefficients were mounted onto the winglets to compensate for the shape of the asymmetric CCP and to keep the released AIRTOSS in a horizontal flight position. More details about the air brakes and the associated flow simulations are given in Sect. 2.6.

During transfer flights into the measurement areas, the unreleased AIRTOSS stayed locked to the winch and was tilted such that it was closely held underneath the wing to ensure a safe distance between sensors and ground during the take-off and landing manoeuvres of the aircraft. The maximum length of the steel wire between the winch and AIRTOSS is $4000 \mathrm{~m}$. During the AIRTOSS-ICE campaign the steel wire was only 
Table 1. Masses of the different instruments and their accessories mounted inside AIRTOSS.

\begin{tabular}{llll}
\hline Component & $\begin{array}{c}\text { Mass } \\
(\mathrm{kg})\end{array}$ & Explanation \\
\hline Front & CCP & 9.10 & Cloud Combination Probe (2-960 $\mu$ m particle diameter) \\
\hline Middle & Rechargeable battery & 10.8 & Power source for all instruments \\
\hline \multirow{2}{*}{ Rear } & Radiation optical inlet & 0.24 & 4 pieces, top and bottom \\
& Spectrometer (near infrared) & 0.56 & 2 pieces, near infrared spectrometer (1000-2200 and 9-16 nm resolution) \\
& Spectrometer (visible) & 1.75 & 2 pieces, visible spectrometer (300-1000 and 3 nm resolution) \\
& Peltier element & 0.33 & 2 pieces \\
& INS & 0.02 & Inertial navigation system \\
& GPS sensor & 0.04 & Global Positioning System \\
& Rosemount and sensors & 0.60 & Temperature and humidity measurements \\
& ICH-TB & 0.40 & Temperature and humidity measurement electronics \\
& Power supply BEP-5150C & 0.75 & Power supply (12 V, 5 V) \\
& Computer & 1.26 & Data acquisition \\
& Shutter & 0.10 & 2 pieces for the SMART system \\
& Shutter control & 0.13 & 2 pieces to control the shutters \\
\hline
\end{tabular}

released to a length of up to $914 \mathrm{~m}$ (3000 ft) to keep AIRTOSS under manageable conditions within the borders of the relatively small restricted military areas. Under these conditions and with an airspeed of $165 \mathrm{~m} \mathrm{~s}^{-1}$, AIRTOSS stayed approximately $180 \mathrm{~m}$ below and $900 \mathrm{~m}$ behind the Learjet. This horizontal displacement introduces a delay of about $5 \mathrm{~s}$ between Learjet and the instantaneous location of AIRTOSS. During turns a lateral displacement is also introduced. These data were rejected from the collocated analysis presented here. The tare weight of the AIRTOSS case without the instruments is $27.0 \mathrm{~kg}$. After including the instruments and the accessories, the total weight is $61.2 \mathrm{~kg}$. To obtain the position of the centre of gravity, a trim weight of $1.4 \mathrm{~kg}$ was added to the rear section, resulting in a total weight of $62.6 \mathrm{~kg}$. This is still less than the maximum permitted total weight of $70 \mathrm{~kg}$. Table 1 gives an overview of the masses of the included instruments and accessories.

\subsubsection{Energy consumption of the instruments}

A rechargeable battery serves as the power source for the instruments mounted inside AIRTOSS and is located in the centre of gravity in the middle section. AIRTOSS reaches a continuous in-air operation time of $2 \mathrm{~h}$. Safety regulations only permit the instrumentation to be powered when AIRTOSS is detached from the Learjet. The consequence of this constraint is that the instruments must start to operate autonomously in an ambient temperature between -30 and $-50^{\circ} \mathrm{C}$. A suitable rechargeable battery for these circumstances is the Smart VHF Modul 20S2P (24 V, $30 \mathrm{Ah})$ from SAFT batteries. To save power, several heaters of the CCP instrument were deactivated. This was possible because the main purpose of the heaters is to avoid icing and condensation at the optics of the instrument, by flying through, e.g. mixed phase clouds. Only those from the CCP Cloud Droplet
Probe (CCP-CDP) instrument (see Sect. 2.3) were running during the measurement flights to keep the electronics under stable temperature conditions. With these settings, all listed instruments in Table 1 consumed $213 \mathrm{~W}$ at a direct current of $28 \mathrm{~V}$. The rechargeable battery delivers $720 \mathrm{Wh}$, which leads to an operating time of $3.5 \mathrm{~h}$. However, considering that the $\mathrm{CCP}$ instrument turns off below a voltage of $22.6 \mathrm{~V}$ in order to protect the lasers, the true operating time of AIRTOSS is $2.5 \mathrm{~h}$.

\subsection{Instrumentation for microphysical cloud particle measurements}

Different in situ instruments were installed on board AIRTOSS and the Learjet sensor pod during the AIRTOSSICE campaign to collect information about the microphysical properties of cirrus clouds. The CCP instrument contained in AIRTOSS is a modified version of the instrument initially manufactured by Droplet Measurement Technologies (DMT, Boulder, CO, USA). The position at the tip of AIRTOSS ensures that the instrument is not influenced by proximity of aircraft structures, wings, and fuselage, which sometimes cause issues when mounted at regular research aircraft (Weigel et al., 2016). To cover particles in a size range between 2 and $960 \mu \mathrm{m}$, the CCP contains a Cloud Imaging Probe greyscale (CCP-CIPg) and a CCP-CDP. Shattering artefacts (Jensen et al., 2009; Korolev et al., 2010) are minimized by using specially designed tips (Korolev et al., 2013) that are mounted on both instruments. Related artefacts can be identified and excluded by using the recorded interarrival time of each particle (Field et al., 2003, 2006; de Reus et al., 2009).

The CCP-CIPg records two-dimensional shadow images in a size range between 15 and $960 \mu \mathrm{m}$ with a resolution of $15 \mu \mathrm{m}$. Computer software, including special algorithms, 
is used afterwards to estimate cloud particle parameters like maximum dimension diameter, concentration, and shape (Korolev, 2007a).

In comparison to the CCP-CIPg instrument, the CCP-CDP detects particles in a smaller particle diameter size range between 2 and $50 \mu \mathrm{m}$. The instrument is based on forward lightscattering with a light collection angle from $4^{\circ}$ up to $12^{\circ}$ and uses a laser diode with a wavelength of $658 \mathrm{~nm}$. A sample area of $0.27 \pm 0.025 \mathrm{~mm}^{2}$ was estimated by using a piezoelectric droplet generator laboratory set-up, similar to the design of Wendisch et al. (1996) and Lance et al. (2010). The accuracy and prior measurements of the CCP-CDP instrument are shown in Molleker et al. (2014) and Klingebiel et al. (2015).

The Learjet was equipped with a Forward Scattering Spectrometer Probe (FSSP) inside the sensor pod (Fig. 1b). This instrument was developed by Knollenberg (1976) to measure particles in a size range between 2 and $47 \mu \mathrm{m}$ in diameter and is a predecessor of the CCP-CDP (Brenguier et al., 2013). Because the FSSP has neither mounted tips nor the feasibility to exclude shattered particles by software algorithms, here it was mainly used for testing purposes and as a cloud indicator during the campaign. In the future it will be replaced with more advanced instrumentation.

\subsection{Spectral solar radiation measurements}

To measure the up- and downward irradiance of a cirrus layer located between the Learjet and AIRTOSS, both platforms were equipped with the Spectral Modular Airborne Radiation measurement sysTem (SMART). For each radiation component (upward/downward irradiance), SMART combines two Zeiss spectrometers, each connected by fibre wires to an optical inlet mounted on the top or at the bottom of AIRTOSS and the Learjet. The spectral range of SMART is between 300 and $2200 \mathrm{~nm}$ with a resolution of $3 \mathrm{~nm}$ for wavelengths below $1000 \mathrm{~nm}$ and $9-16 \mathrm{~nm}$ above (Wendisch et al., 2001; Bierwirth et al., 2009). The upward-looking irradiance sensor on the Learjet was placed on a stabilized platform to keep it horizontally aligned during the flights.

Due to the limited space inside AIRTOSS (see Fig. 2a), an active horizontal stabilization of the radiation sensors could not be realized. For this reason an inertial navigation system (INS) in combination with a Global Positioning System (GPS) was used to record attitude and alignment angles. These data were screened afterwards to identify and remove sections where reliable measurements were not possible. A detailed analysis of the solar radiation instruments, the measurements in cirrus, and the scientific results of the AIRTOSS-ICE campaign are given in Finger et al. (2016).

\subsection{Trace gas instruments}

Besides the radiation and microphysical instruments, the AIRTOSS-Learjet tandem platform was equipped with a suite of instruments quantifying the concentration of different trace gases.

The Fast Aircraft-Borne Licor Experiment (FABLE) was integrated on the Learjet to detect the amount of carbon dioxide $\left(\mathrm{CO}_{2}\right)$ at flight altitude (Gurk et al., 2008). Nitrous oxide $\left(\mathrm{N}_{2} \mathrm{O}\right)$ and carbon monoxide $(\mathrm{CO})$ were measured with the University of Mainz Airborne QCL-Spectrometer (UMAQS; see Müller et al., 2015 for details).

Temperature and relative humidity measurements were made on the Learjet and on AIRTOSS by the MOZAIC Capacitive Hygrometer (MCH), which belongs to the Measurement of Ozone by Airbus In-Service Aircraft (MOZAIC) system. The MCH uses a capacitative sensor and a Pt100 element to measure the relative humidity and the temperature respectively. The accuracy is $\pm 0.5^{\circ} \mathrm{C}$ for the temperature measurement and $\pm 5 \%$ for the detection of the relative humidity. Evaluation and measurement methods of the $\mathrm{MCH}$ are described in detail in Neis et al. (2015).

Water vapour measurements were taken by the Fast InSitu Hygrometer instrument (FISH) and the Selective Extractive Airborne Laser Diode Hygrometer II (SEALDHII). The FISH instrument is developed and operated by the Forschungszentrum Jülich. It is based on Lyman-AlphaPhotometry and detects water vapour in a range between 1 and $1000 \mathrm{ppmv}$ with an uncertainty of $\pm 0.2 \mathrm{ppmv}$ (Zöger et al., 1999). SEALDH-II is operated by the PhysikalischTechnischen Bundesanstalt, uses direct tunable diode laser absorption (dTDLAS) and leads without any previous gasbased instrument calibration to an absolute $\mathrm{H}_{2} \mathrm{O}$ concentration value. It operates in a detection range between about $30 \mathrm{ppmv}$ and roughly $40000 \mathrm{ppmv}$ with an accuracy of $0.35 \%$ and a time resolution of $<1 \mathrm{~s}$ (Buchholz et al., 2016; Buchholz and Ebert, 2017).

Ozone $\left(\mathrm{O}_{3}\right)$ measurements were performed on the Learjet by using a UV photometry $42 \mathrm{M}$ ozone analyser developed by Environment S.A. This instrument detects the UVabsorption caused by $\mathrm{O}_{3}$ at a wavelength of $254 \mathrm{~nm}$ in a measurement range between $0.9 \mathrm{ppb}$ (at $700 \mathrm{hPa}$ ) and $10000 \mathrm{ppb}$ with an uncertainty of $10 \%$ (Köllner, 2013).

These instruments can be used for independent trace gas dynamics studies (e.g. Müller et al., 2015) to better find the exact location of the tropopause and identify tropopause folds as well as stratospheric influence on uppermost tropospheric cirrus clouds (especially subvisual cirrus), finding borders of air masses (e.g. the polar dome), among others.

\subsection{Flow simulations}

With the incorporation of the CDP component of the CCP, the AIRTOSS overall geometry has been altered in comparison with the design shown by Frey et al. (2009). Since the CDP is axially non-symmetric, the aerodynamic properties of AIRTOSS were correspondingly modified with largely unknown effects on alignment, attitude, and behaviour during flight. Figure 3a shows a front view of AIRTOSS, which 
(a)
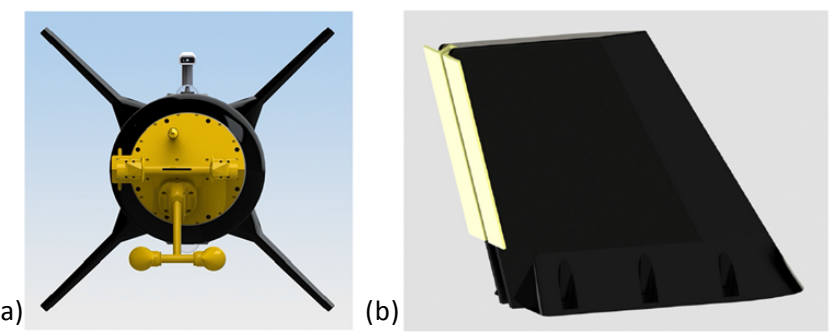

Figure 3. (a) Front view of the AIRTOSS showing the asymmetrical shape of the CCP instrument. (b) Air brake at one wing of the AIRTOSS (Röschenthaler, 2013).

demonstrates the asymmetry introduced by the CDP. To investigate these effects in regard to ensuring stable flight conditions, detailed fluid flow simulations of the AIRTOSS aerodynamics have been performed (Röschenthaler, 2013) by employing a computational fluid dynamics (CFD) methodology. We recall that, for the formal Airworthiness Directives certification of the AIRTOSS, the corresponding simulations resulting in the evolution of the forces and drag coefficients were mandatory. The 3-D calculations were performed using the AVL FIRE Thermo-Fluid Simulation Software (by AVLList GmbH, Graz, Austria; AVL-Fire, 2013), employing a finite volume discretization method based on the integral form of the general conservation law applied to polyhedral control volumes. The turbulence model that was adopted is a fourequation, eddy-viscosity-based turbulence model denoted by $k-\varepsilon-\zeta-f$ (Hanjalić et al., 2004). Application of the "concept of elliptic relaxation" allows for particular attention to the flow effects close to the walls when approaching the AIRTOSS surface. In addition to the equations governing the kinetic energy of turbulence $k$ and its dissipation rate $\varepsilon$, it solves transport equations for the quantity $\zeta$, representing the ratio $\overline{v^{2}} / k$, and elliptic function $f$, with $\overline{v^{2}}$ denoting the scalar variable which behaves as the normal-to-the-wall Reynolds stress component by approaching the solid wall. Here, the $\zeta$ quantity represents a key parameter, as it models the near-wall anisotropy influence on the relevant velocity scale in the corresponding formulation for the turbulent viscosity. The compound wall functions, blending between the integration up to the wall with the standard equilibrium wall functions, were applied for the wall treatment. They are especially advantageous for the high Reynolds number flows, enabling well-defined boundary conditions irrespective of the position of the wall-closest computational node. The numerical grid discretizing the object surface and its surroundings consists of 12.7 million cells; this grid represents an appropriate refinement of a coarser grid comprising 6.9 million cells. The MINMOD bounded scheme combining the second-order accurate schemes CDS (central differencing scheme) and LUDS (linear upwind differencing scheme) is utilized for the discretization of the convective transport and the conventional CDS scheme for the diffusive transport.
As a result detailed flow velocity fields were obtained as well as the fields of turbulence quantities, drag coefficients, and aerodynamic forces. The drag calculations were of specific concern because the connecting steel wire only has a diameter of $2 \mathrm{~mm}$. As an illustration Fig. 4a shows the resulting total body pressure calculated by the CFD simulation for flight conditions in the upper troposphere (i.e. here $25000 \mathrm{ft}$, $7620 \mathrm{~m})$ at aircraft speeds near $172 \mathrm{kt}\left(319 \mathrm{kmh}^{-1}\right)$. The highest total pressure regions occur in the front of the CCP instrument and at the edges of the tail stabilizers in the rear part of AIRTOSS. Regimes with a lower total pressure indicate flow conditions associated with lower turbulence level in connection with the flow acceleration. Figure $4 \mathrm{~b}$ provides an example of the typical velocity distribution around the AIRTOSS body. The deceleration zone, as identified by Weigel et al. (2016) in the region of the CCP measurement volume corresponding to its front surface, can be well discerned on the left side of the graph. The acceleration regions (red coloured areas) originating from the streamline curvature effects follow. Figure $4 \mathrm{c}$ shows an iso-surface of the turbulent kinetic energy with a value of $150 \mathrm{~m}^{2} \mathrm{~s}^{-2}$ coloured by the velocity magnitude. Here the highest speeds occur downstream of the CCP's measurement volume. As an overall result of the CFD simulations, the horizontal tail stabilizers of the AIRTOSS body were modified by affixing small air brakes to them in suitable positions such that the asymmetry effects of the CDP were fully compensated (see Fig. 3b). Accordingly, during level flights AIRTOSS moved quietly in the flow, without disturbing oscillations, and the stable attitude necessary for the radiation measurements was maintained well.

\section{Results from the cirrus measurements during AIRTOSS-ICE}

On 4 September 2013, the northern part of Germany was located between a high-pressure system with its centre above southern Germany and a low-pressure system above Scandinavia. A related warm front in combination with cirrus passed the measurement area above the Baltic Sea (Fig. 5). The cirrus deck was probed by the AIRTOSS-Learjet tandem platform between 09:10 and 09:40 UTC. The observations indicated that the cirrus was located at an altitude between 8100 and $10200 \mathrm{~m}$ with temperatures between -30 and $-46^{\circ} \mathrm{C}$. Ice particle number concentrations of up to $1.4 \mathrm{~cm}^{-3}$ were found in several patches by the CCP in the upper cloud layer $(>9000 \mathrm{~m}$ ) where temperatures ranged below $-40^{\circ} \mathrm{C}$. As discussed by Kärcher and Lohmann (2002), these high ice particle number concentrations only occur with vertical velocities higher than $30 \mathrm{~cm} \mathrm{~s}^{-1}$. Updraughts in warm fronts typically have vertical speeds of less than $10 \mathrm{~cm} \mathrm{~s}^{-1}$ (Heymsfield, 1977) and cannot explain these high ice particle number concentrations. It appears that local convective cells with stronger updraughts lifted droplets from 
(a)

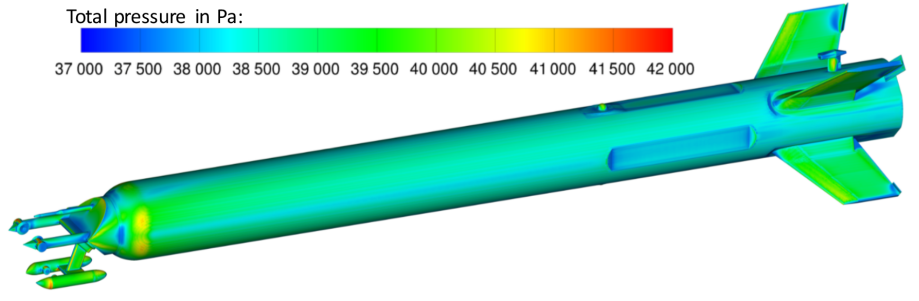

(b)

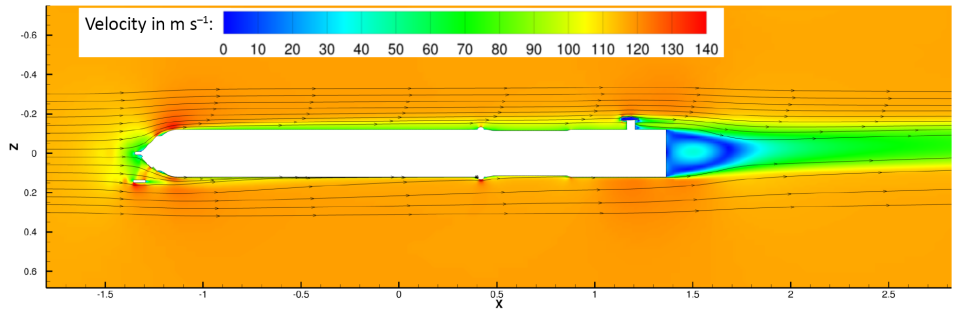

(c)

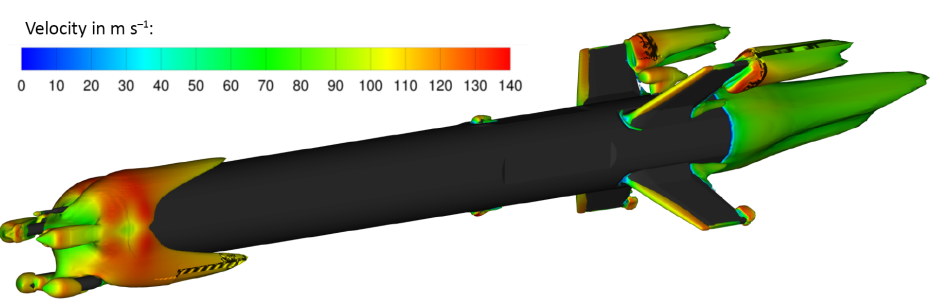

Figure 4. Flow simulations for flight conditions: (a) resulting total body pressure, (b) velocity distribution around the AIRTOSS body, (c) iso-surface of the turbulent kinetic energy with a value of $150 \mathrm{~m}^{2} \mathrm{~s}^{-2}$ coloured by the velocity magnitude (Röschenthaler, 2013).

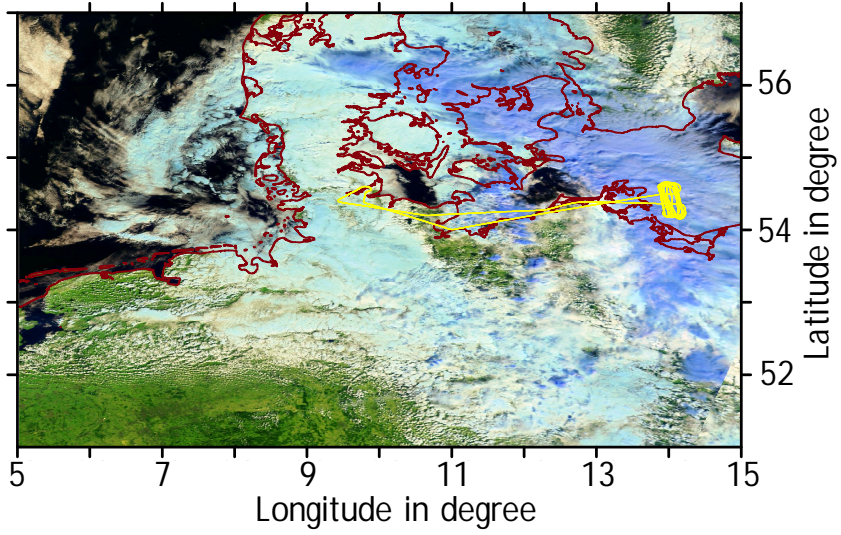

Figure 5. MODIS high-resolution picture of the northern part of Germany, taken at 11:00 UTC on 4 September 2013. Low stratus clouds are marked in white and the observed cirrus is marked in blue. The yellow line indicates the flight path of the Learjet.

lower cloud layers to the cirrus altitude. As a result, homogeneous freezing in the cirrus environment might have been initiated and would explain the high ice particle number concentrations in the upper part of the cirrus.

\subsection{Microphysical measurements}

The flight paths of AIRTOSS and the Learjet are shown in Fig. 6. The colour-coded line in Fig. 6a shows the mean ice particle diameter measured by the CCP-CIPg. For each altitude a mean particle number size distribution was calculated. The flight sections at constant altitude that were used for the averaging are marked in Fig. 6a. The legs were executed on constant altitude levels and are longer in the lower part of the cloud to obtain appropriate counting statistics for the optical particle instruments. Figure 7 displays the corresponding particle number size distributions and 2-D shadow images, detected by the CCP for every single flight leg. The total particle number concentration $N$ is provided in Fig. 7a and shows a typical increase with altitude from $0.26 \times 10^{-2} \mathrm{~cm}^{-3}$ (8716 m) to $8.4 \times 10^{-2} \mathrm{~cm}^{-3}(9939 \mathrm{~m})$. Also, the particle size corresponding to the maximum of the size distributions shifts with decreasing altitude from $30 \mu \mathrm{m}(9939 \mathrm{~m})$ to $300 \mu \mathrm{m}$ $(8716 \mathrm{~m})$. The increase in particle diameter with decreasing altitude is also obvious in the 2-D shadow images (Fig. 7b). Higher ice particle number concentrations with small particle diameters in the upper cloud layers and lower ice particle number concentrations with large particle diameters in the lower cloud layers are typical for frontal, midlatitude cirrus and result from the microphysical growth process during the formation of the cirrus. As long as the relative humidity with respect to ice is sufficiently high, the particles start to grow by water vapour diffusion, gain mass, and sediment. This sedimentation process leads to a redistribution of the ice particles inside the cirrus, with higher particle concentrations and smaller cirrus particles at cloud top. Nevertheless, the irregular particle shapes of the 2-D shadow im- 

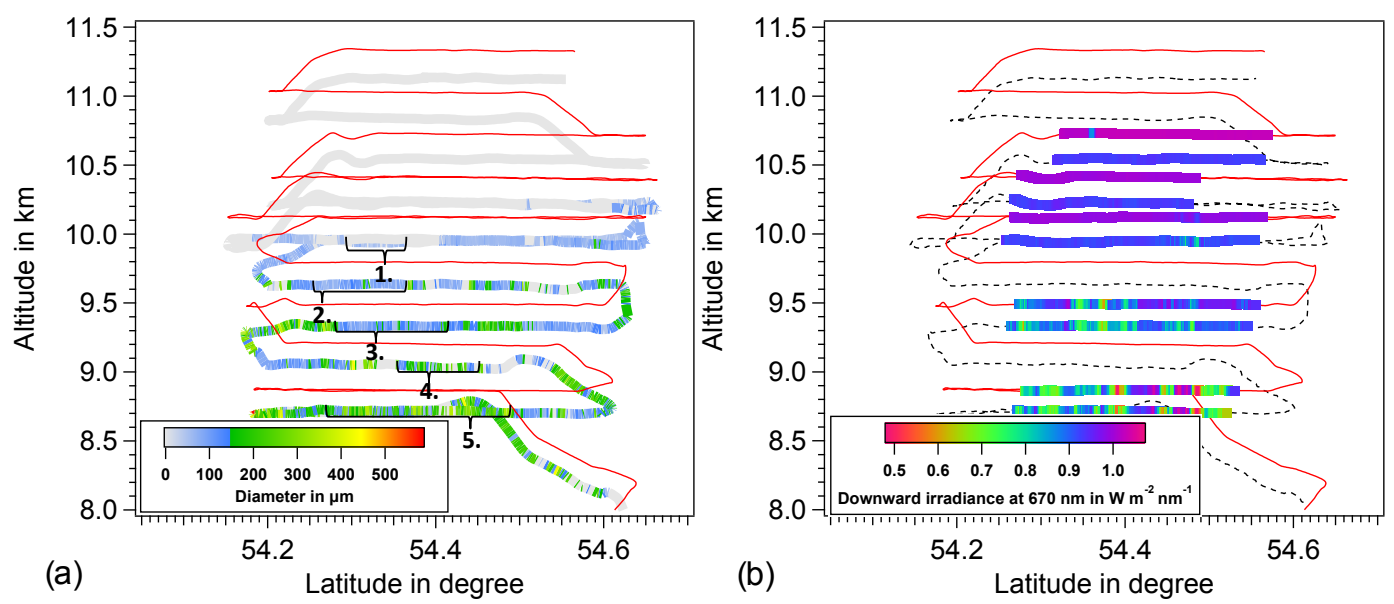

Figure 6. Both panels show the flight path of the Learjet (red line) and the flight path of AIRTOSS (dashed line) on 4 September 2013 with an overlay showing colour-coded measurements of particle mean diameter (a) and downward irradiance at $670 \mathrm{~nm}$ (b). The flight sections used to calculate the mean particle diameter for specific legs are indicated in (a).

ages in the lower part of the cirrus indicate that aggregation could also be a possible particle growth process. To analyse whether diffusion or aggregation is the dominant process inside the observed cirrus, similarly to Heymsfield and Westbrook (2010), terminal velocities were calculated. This is done by using the particle diameter $D_{\mathrm{p}}$ and the area ratio, which is the area of the shadowed pixels (detected by the CCP-CIPg) divided by the calculated particle area using the maximum dimension diameter (Frey, 2011). As an example, a spherical (area ratio $=1$ ) and a horizontal-orientated column-shaped (area ratio $=0.25$ ) ice particle with an initialized diameter of $D_{\mathrm{p}}=200 \mu \mathrm{m}$ are assumed. This represents the measured conditions during Flight Leg 3 at an altitude of $9333 \mathrm{~m}$ (see Fig. 7). For the spherical particle, a terminal velocity of $v_{\mathrm{t}}=91 \mathrm{~cm} \mathrm{~s}^{-1}$ was calculated, while for the horizontal-orientated columnar particle $v_{\mathrm{t}}=14.5 \mathrm{~cm} \mathrm{~s}^{-1}$ was estimated. With these estimated terminal fall velocities, the particles would need 11 and $71 \mathrm{~min}$, respectively, until they reach the bottom layer of the cloud at an altitude of $8716 \mathrm{~m}$. Following the discussion by Kienast-Sjögren et al. (2013), particles with a number concentration of $5.8 \times 10^{-2} \mathrm{~cm}^{-3}$ (Level 3 in Fig. 7) need at least several hours before aggregation processes occur, because the probability for collision is low. For this reason, aggregation is unlikely, and diffusional growth seems to be the dominant process for this particular cirrus observed during AIRTOSS-ICE.

\subsection{Solar downward irradiance}

In addition to the microphysical measurements, collocated measurements of spectral solar radiation were performed during the cirrus event of Sect. 3.1. Similar to Fig. 6a, a profile of the spectral downward irradiance (at $670 \mathrm{~nm}$ wavelength) measured by SMART on AIRTOSS and Learjet is given in Fig. 6b. The individual legs were filtered for turns

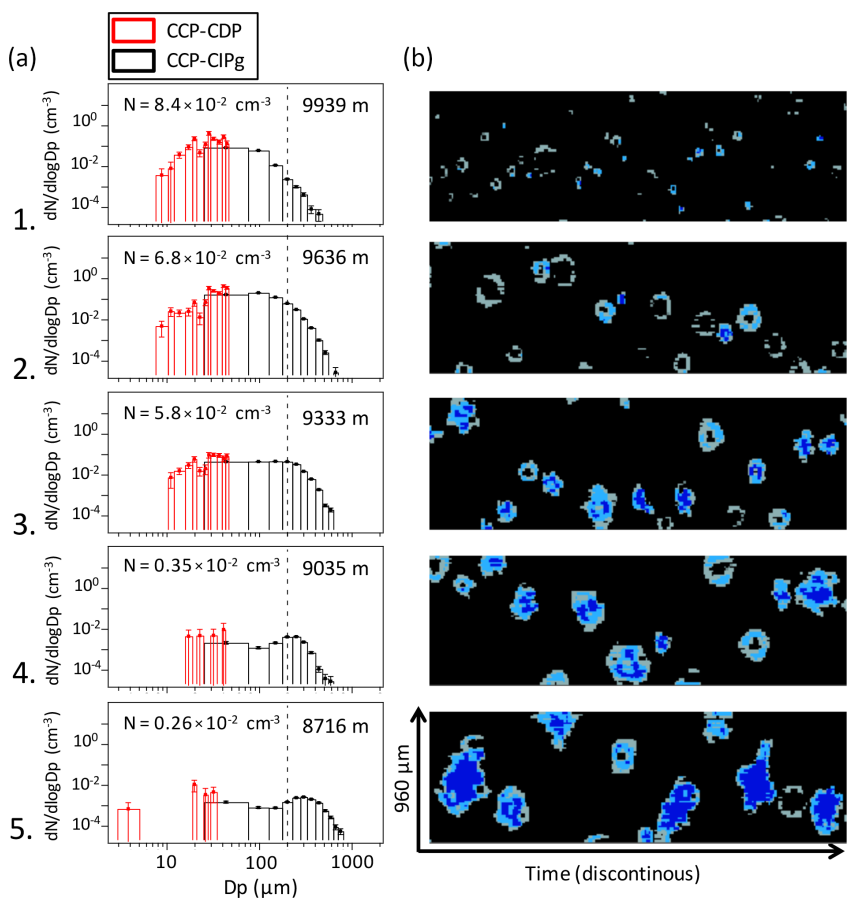

Figure 7. Microphysical characteristics of the marked flight legs from Fig. 6a. (a) Combined size distributions of the CCP-CDP (red) and the CCP-CIPg (black) instrument mounted on the AIRTOSS. With an increasing altitude, the maximum of the size distribution shifts to smaller particle diameters. (b) Sample 2-D shadow images from every single flight leg, recorded by the CCP-CIPg instrument. The different colours represent the shadow intensity (grey $>35 \%$, light blue $>50 \%$, dark blue $>65 \%$ ).

of both platforms which assures that only level flight conditions were considered. Additionally, only legs flown in the same direction and above the same locations were chosen to 


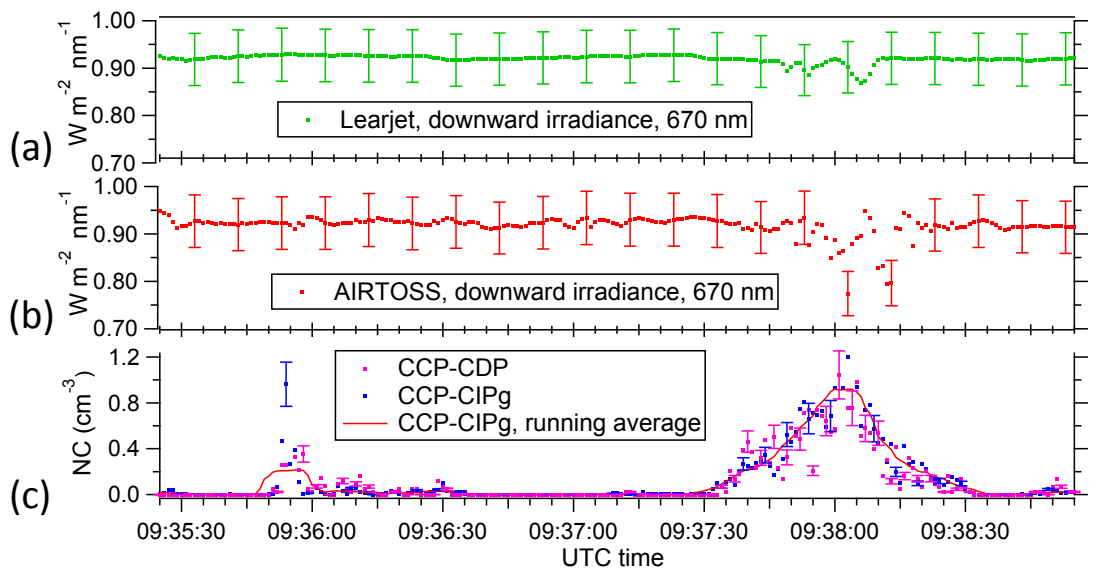

Figure 8. Downward spectral irradiance at $670 \mathrm{~nm}$ measured from the (a) Learjet and (b) AIRTOSS as well as the (c) number concentration (NC) measured on the AIRTOSS platform with the CCP-CDP $(2-50 \mu \mathrm{m})$ and the CCP-CIPg $(15-960 \mu \mathrm{m})$ instruments. The data were obtained at the highest flight leg and measured on 4 September 2013, where AIRTOSS flew at an altitude of around $9900 \mathrm{~m}$. The vertical bars indicate the error of the instruments, and the running average uses the boxcar smoothing algorithm with 10 repetitions.

assure similar cloud and surface conditions below the cirrus. In total, five legs with simultaneous measurements on AIRTOSS and the Learjet are available with larger vertical separation in the cirrus and less separation at cloud top and above. The impact of the cirrus on the downward irradiance is most obvious in the two lower legs where the radiation is attenuated by the cirrus. The attenuation is highly variable due to the horizontal heterogeneity of the cirrus. However, both sensors on AIRTOSS and Learjet show almost the same pattern, illustrating the collocation of the measurements. The similarity in the two data sets also results from the small vertical displacement of Learjet and AIRTOSS of less than $200 \mathrm{~m}$. During the higher flight legs, the attenuation of downward irradiance by the cirrus is significantly lower. In the third leg, only AIRTOSS measurements are slightly affected by the cirrus, while the Learjet already observed clear-sky conditions. Above the cirrus, the downward irradiance is almost constant over the entire legs, indicating clear sky for both platforms.

\section{Discussion}

Two cases are selected to illustrate the potential of the collocation of measurements achieved by the AIRTOSS-Learjet tandem platform. Due to the different instruments that are operated on AIRTOSS and Learjet, different combined analysis of data are possible. Beside combining in situ and radiation measurements the simultaneous radiation measurements on both platforms can also be analysed jointly.

\subsection{Collocation of microphysical and radiative properties}

Figure 8 shows a time series of downward spectral irradiance at $670 \mathrm{~nm}$ wavelength measured from the Learjet (Fig. 8a) and AIRTOSS (Fig. 8b) during a flight leg observed on 4 September 2013 between 09:35 and 09:39 UTC, when AIRTOSS was operated at an altitude of around $9900 \mathrm{~m}$. In addition, Fig. 8c shows the detected number concentration of the CCP-CDP and the CCP-CIPg. The cloud particle number concentrations above zero were detected within two sections of the flight leg and indicate that AIRTOSS penetrated two cirrus filaments at the top of the cirrus layer. The downward irradiance has been constant for most of the flight leg, indicating clear-sky conditions without attenuation of the incoming solar radiation. The strongest deviation from the clearsky conditions was found at about 09:38:05 UTC, when the irradiance shows a rapid decrease for both platforms.

This coincides with higher values in the particle number concentration measurements. The increasing number concentration indicates that AIRTOSS is located in a thicker part of the sampled cloud and certainly the cloud top is above AIRTOSS. As the Learjet measurements are located closer to cloud top, the effect here is smaller compared to the AIRTOSS observations. At cloud edges also an increase of the irradiance can occur due to three-dimensional radiative effects (Sabburg and Long, 2004). For the smaller cloud observed at the beginning of the leg (09:35:45-09:36:40 UTC), only the downward irradiance measured by AIRTOSS shows variation, while the downward irradiance measured by the instruments on the Learjet remains almost constant. At this time only AIRTOSS was located inside the cirrus while the Learjet flew above cloud top and consequently only the downward radiation in the altitude of AIRTOSS was reduced.

Such constellations are well suited to investigate the interaction of cloud microphysical and radiative properties as demonstrated by Werner et al. (2014) for shallow cumulus. However, the approach by Werner et al. (2014) for analysing the collocated number concentration and cloud remote sens- 


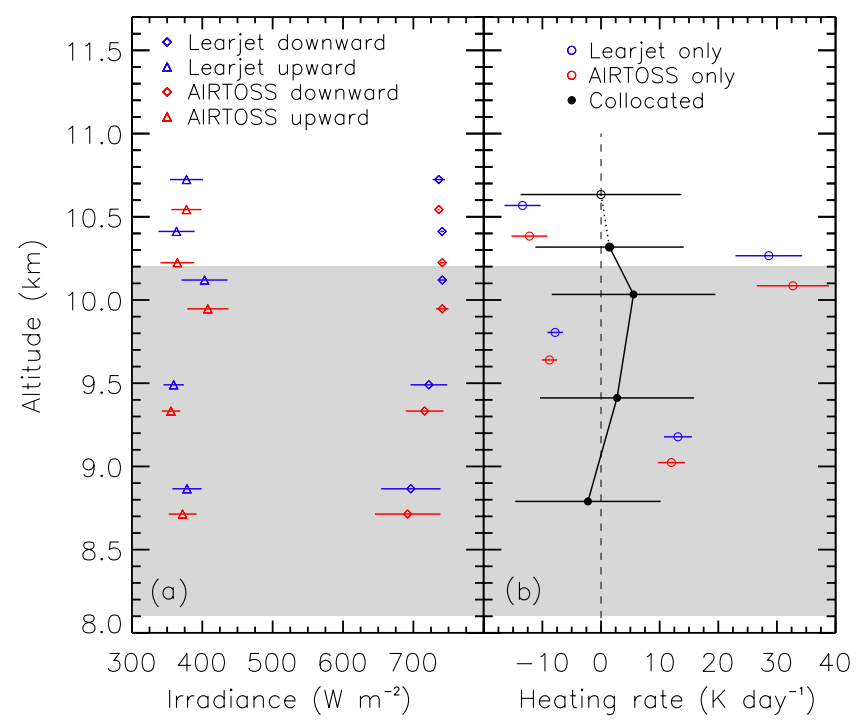

Figure 9. (a) Profiles of vertical upward and downward broadband irradiance measured on AIRTOSS and the Learjet. The bars indicate the standard deviation of the irradiance along the individual flight legs. (b) Solar heating rates calculated from the irradiance profile using either a single platform or the collocated measurements. The grey area indicates the cirrus layer as indicated by the CCP.

ing works only if the radiation measurements are taken well above the cloud. In the case of the AIRTOSS-Learjet tandem this would limit the analysis to the uppermost cirrus layer. However, when operating radiation measurements on both platforms, the cloud optical layer properties can be derived as presented by Finger et al. (2016). Using the collocation, cloud layers well inside the cloud can also be analysed.

\subsection{Vertical profile of solar heating rates}

The spectral irradiance measurements were integrated to broadband quantities and averaged for the individual horizontal legs as indicated in Fig. 6. To make measurements comparable, the change of the solar position in between measurements of the different legs was taken into account by normalizing the irradiance to observations from the uppermost level. Figure 9a shows the corresponding vertical profiles of upward and downward broadband irradiance measured on AIRTOSS and Learjet. The horizontal bars indicate the standard deviation of the irradiance along the individual flight legs.

The upward irradiance varies significantly with altitude albeit without showing a regular pattern. This is likely caused by slight changes of the flight track and the in-cloud situation, mainly the presence of a low stratus cloud below the cirrus (see Fig. 5). The standard deviation of upward irradiance is higher in the upper three legs, while the two lower legs show less variability when the sensors are located well below cloud top. Assuming, that along the flight leg the low stratus is homogeneous with respect to the field of view of the irradiance optical inlet, these higher standard deviations are mainly caused by the spatial variability of the cirrus. The cirrus is located vertically closer to the irradiance sensor and therefore smaller horizontally inhomogeneities are resolved by the measurements.

The profile of downward irradiance also indicates the presence of cirrus. While above cloud top the values remain vertically constant and show only a small standard deviation, larger variability and a decrease of the downward irradiance are observed when the instruments enter the cloud. Upward and downward irradiance $F^{\downarrow}$ and $F^{\uparrow}$ at two different altitudes, $z_{1}$ and $z_{2}$ are used to calculate the effect of the radiation field on the local temperature change in terms of heating rates at a certain altitude $z=1 / 2 \cdot\left(z_{1}+z_{2}\right)$. The heating rate $\partial T /\left.\partial t\right|_{z}$ in units of $\mathrm{Kday}^{-1}$ within the layer is derived following Wendisch and Yang (2012) (Eq. 9.66):

$$
\begin{aligned}
\left.\frac{\partial T}{\partial t}\right|_{z} & =\frac{1}{\varrho \cdot c_{\mathrm{p}}} \cdot \frac{\partial F_{\text {net }}(z)}{\partial z} \\
& \approx \frac{1}{\varrho \cdot c_{\mathrm{p}}} \cdot\left[\frac{F_{\mathrm{net}}\left(z_{2}\right)-F_{\mathrm{net}}\left(z_{1}\right)}{z_{2}-z_{1}}\right] \\
& \approx \frac{1}{\varrho \cdot c_{\mathrm{p}}} \cdot\left\{\frac{\left[F^{\downarrow}\left(z_{2}\right)-F^{\downarrow}\left(z_{1}\right)\right]-\left[F^{\uparrow}\left(z_{2}\right)-F^{\uparrow}\left(z_{1}\right)\right]}{z_{2}-z_{1}}\right\} .
\end{aligned}
$$

Figure $9 \mathrm{~b}$ shows profiles of $\partial T /\left.\partial t\right|_{z}$ derived in two different ways. Assuming only a single aircraft is available, the solar heating rates can be calculated by the irradiance profile measured by this single aircraft, either AIRTOSS (red circles) or Learjet alone (blue circles). Having the combined collocated measurements of both AIRTOSS and Learjet, heating rates can additionally be derived along each horizontal leg (black circles). The heating rate profiles obtained for the investigated cirrus significantly differ depending on the chosen method. To interpret these differences, uncertainties of the heating rates were calculated for both approaches. An uncertainty of $6 \%$ in the radiometric calibrations was assumed, which directly propagates into the calculated heating rates (Eq. 1) as all sensors are calibrated identically. All remaining uncertainties of the irradiance are estimated with $0.5 \%$. For the single-aircraft approach the irradiances are always measured with the same system. This reduces the impact of the remaining uncertainty to contributions of the two net irradiance only. In the collocated approach, two independent systems are used and all four irradiance measurements contribute to the overall uncertainty. Additionally, the distance $z_{2}-z_{1}$ influences the accuracy of the heating rate. Due to the geometry and the flight altitudes, this distance differs for both approaches. Larger distances between the two measurements provide more precise results. While $z_{2}-z_{1}$ amounts to about $200 \mathrm{~m}$ for the collocated approach, determined by the length of the wire between AIRTOSS and the Learjet, $z_{2}-z_{1}$ of the single-aircraft approach depends on the altitudes of the legs and is typically larger $(500 \mathrm{~m}$ at cloud bottom and $300 \mathrm{~m}$ at cloud top). Overall, the uncertainty of the heating rate estimates derived from the collocated approach are theoretically 
expected to be significant larger than for the single-aircraft approach. However, although the profiles using only AIRTOSS and only Learjet data agree with each other, the profiles show large scatter with heating rates ranging from -13 to $+33 \mathrm{Kday}^{-1}$. These unrealistic heating rates mainly result from changes in the upward irradiance between two individual flight legs. As the legs are not perfectly collocated and a low stratus layer did change its location below the cirrus during a flight level change ( $\sim 2$ min temporal separation), the data set is not consistent and leads to incorrect heating rate estimates.

By contrast, the collocated data set does not suffer from changing conditions below the cirrus as both sensors always observe the same scene at the same time. Consequently, the heating rate profile in Fig. $9 \mathrm{~b}$ does show a smoother and more realistic pattern with values always ranging between 0 and $6 \mathrm{~K} \mathrm{day}^{-1}$, which are typical values for a thin cirrus.

This improvement in calculating heating rates illustrates the benefit of collocated irradiance measurements. However, the derived heating rates still do not represent theoretical results as provided, for example, by Bucholtz et al. (2010) and Thorsen et al. (2013). For subvisible and optically thin cirrus, they calculated heating rates in the range of $0.2-0.5 \mathrm{~K} \mathrm{day}^{-1}$. These higher values might result from the higher optical thickness, $\tau=0.6$, of the cirrus observed by AIRTOSS or be caused by horizontal inhomogeneities of the observed cirrus leading to horizontal photon transport as discussed by Finger et al. (2016).

\section{Conclusions}

The advanced AIRTOSS-Learjet tandem platform was applied during the AIRTOSS-ICE campaign to perform collocated measurements of cirrus cloud properties. A combination of the Learjet and AIRTOSS, both equipped with radiation and microphysical in situ instruments, allowed for measurements of cirrus properties at different altitudes using just one aircraft. The new certification for the AIRTOSS-Learjet tandem platform enabled us to probe cirrus at altitudes up to $36000 \mathrm{ft}(10970 \mathrm{~m})$. The campaign showed that collocated measurements with the revised AIRTOSS-Learjet tandem platform are feasible. This is demonstrated by combining the microphysical and radiative measurements and, as an illustrative example, by deriving solar heating rates. Further results are presented by Finger et al. (2016) in a closure study, which combines in situ cloud and radiative measurements to quantify the impact of ice crystal shape, effective radius, and optical thickness on cirrus radiative forcing.

A case study is presented in which AIRTOSS-ICE measurements are used to derive vertical profiles of cloud microphysical and radiative properties. Using the profiles of upward and downward irradiances, it is shown that solar heating rates can be estimated with improved accuracy when collocated measurements are applied, instead of using a sin- gle platform. Despite the expected higher uncertainties introduced by the measurement errors from two independent measurement systems, the collocated observations resulted in a more realistic profile of solar heating rates as these are not affected by changes of the radiation field below the observational altitude (e.g. inhomogeneous surface albedo, lower cloud layers). Observations performed with a single aircraft strongly depend on stable conditions between consecutive flight legs and, therefore, are subject to serious uncertainties in derived profiles of solar heating rates.

However, AIRTOSS-ICE also showed the limits of the collocated measurement set-up. The investigated cirrus had a thickness of more than $200 \mathrm{~m}$, which is larger than the distance between Learjet and AIRTOSS during the conducted measurement example. This did not allow for the radiative instruments to measure concurrently with AIRTOSS below the cirrus layer and with the Learjet above, which would have been needed to derive the cirrus radiative layer properties (Finger et al., 2016). The short distance between both platforms resulted in only small differences in the upward and downward irradiances measured on AIRTOSS and the Learjet for this sampling example. An increase of the vertical distance beyond $200 \mathrm{~m}$ is not easy to achieve. It would require a longer steel wire and/or a slower aircraft as well as larger areas where such flights are permitted. For clouds with a larger vertical extent, two single aircraft could be a better choice. It certainly depends on the scientific goals and instrumentation as to whether or not the AIRTOSS-Learjet tandem platform is the appropriate choice.

With respect to microphysical inhomogeneities, the vertical separation of $200 \mathrm{~m}$ between both platforms is sufficient for cirrus studies. What would be required additionally are microphysical in situ instruments with overlapping measurement characteristics, or, ideally, two identical instrument sets on both platforms. To perform microphysical measurements with a higher temporal resolution, the implementation of holographic instruments is also an attractive alternative. These instruments have a larger sample volume of up to $305 \mathrm{~cm}^{3}$ (Schlenczek et al., 2016), which is much higher than the sample volume of the CCP-CDP $\left(45 \mathrm{~cm}^{3}\right.$ for an aircraft velocity of $165 \mathrm{~m} \mathrm{~s}^{-1}$ ). Furthermore, the integration of trace gas instruments inside AIRTOSS and the Learjet could be used, e.g. for collocated trace gas measurements in the vicinity of the tropopause layer, the edges of tropopause folds, and streamers. To study different atmospheric conditions or to obtain better statistics of cirrus cloud, the operation of the AIRTOSS-Learjet tandem platform in other regions, outside of military restricted areas, remains a significant challenge. This could be accomplished in less populated areas, such as the polar regions, remote areas of the oceans, and rainforests.

Data availability. All data are available from the authors upon request. For the spectral solar radiation measurements contact the University of Leipzig (a.ehrlich@uni-leipzig.de). The microphys- 
ical measurements are accessible by contacting the corresponding author (stephan.borrmann@mpic.de) or the first author (marcus.klingebiel@mpimet.mpg.de).

Competing interests. The authors declare that they have no conflict of interest.

Acknowledgements. The AIRTOSS-ICE project was supported by the Deutsche Forschungsgemeinschaft (DFG) through projects "WE 1900/19-1, BO 1829/7-1, SP 1163/3-1" and on a significant level by internal funds of the Particle Chemistry Department at the Max Planck Institute for Chemistry. We particularly thank the pilots and the crew of the Gesellschaft für Flugzieldarstellung for making this project possible. We are also thankful for the support of the electrical engineers Wilhelm Schneider and Christian von Glahn (University of Mainz) and all other participants of the AIRTOSS-ICE campaign.

The article processing charges for this open-access publication were covered by the Max Planck Society.

Edited by: Szymon Malinowski

Reviewed by: two anonymous referees

\section{References}

AVL-Fire: Programme Manual, CFD Solver Version 2013, AVL List GmbH, Graz, Austria, 2013.

Bierwirth, E., Wendisch, M., Ehrlich, A., Heese, B., Tesche, M., Althausen, D., Schladitz, A., Müller, D., Otto, S., Trautmann, T., Dinter, T., von Hoyningen-Huene, W., and Kahn, R.: Spectral surface albedo over Morocco and its impact on the radiative forcing of Saharan dust, Tellus B, 61, 252-269, https://doi.org/10.1111/j.1600-0889.2008.00395.x, 2009.

Brenguier, J., Bachalo, W. D., Chuang, P. Y., Esposito, B. M., Fugal, J., Garrett, T., Gayet, J.-F., Gerber, H., Heymsfield, A., Kokhanovsky, A., Korolev, A., Lawson, R. P., Rogers, D. C., Shaw, R. A., Strapp, W., and Wendisch, M.: In situ measurements of cloud and precipitation particles, in: Airborne Measurements for Environmental Research: Methods and Instruments, edited by: Wendisch, M. and Brenguier, J.-L., Wiley-VCH Verlag GmbH \& Co. KGaA, Weinheim, Germany, https://doi.org/10.1002/9783527653218.ch5, 2013.

Bucholtz, A., Hlavka, D. L., McGill, M. J., Schmidt, K. S., Pilewskie, P., Davis, S. M., Reid, E. A., and Walker, A. L.: Directly measured heating rates of a tropical subvisible cirrus cloud, J. Geophys. Res., 115, D00J09, https://doi.org/10.1029/2009JD013128, 2010.

Buchholz, B. and Ebert, V.: SEALDH-II - a calibration-free transfer standard for airborne water vapor measurements: Pressure dependent absolute validation from 5-1200 ppmv at a metrological humidity generator, Atmos. Meas. Tech. Discuss., https://doi.org/10.5194/amt-2016-413, in review, 2017.

Buchholz, B., Kallweit, S., and Ebert, V.: SEALDH-II An Autonomous, Holistically Controlled, First Principles TDLAS Hygrometer for Field and Airborne Applications: Design-Setup-
Accuracy/Stability Stress Test, Sensors (Basel, Switzerland), 17, 68, https://doi.org/10.3390/s17010068, 2016.

de Reus, M., Borrmann, S., Bansemer, A., Heymsfield, A. J., Weigel, R., Schiller, C., Mitev, V., Frey, W., Kunkel, D., Kürten, A., Curtius, J., Sitnikov, N. M., Ulanovsky, A., and Ravegnani, F.: Evidence for ice particles in the tropical stratosphere from in-situ measurements, Atmos. Chem. Phys., 9, 6775-6792, https://doi.org/10.5194/acp-9-6775-2009, 2009.

Ehrlich, A. and Wendisch, M.: Investigation of Arctic mixed-phase clouds during VERDI and RACEPAC: Combining airborne remote sensing and in situ observations, EGU General Assembly, Vienna, Austria, 17-22 April 2016, EGU2016-14467-1, 2016.

Eichler, H., Ehrlich, A., Wendisch, M., Mioche, G., Gayet, J.F., Wirth, M., Emde, C., and Minikin, A.: Influence of ice crystal shape on retrieval of cirrus optical thickness and effective radius: A case study, J. Geophys. Res., 114, D19203, https://doi.org/10.1029/2009JD012215, 2009.

Field, P. R., Wood, R., and Brown, P. R. A.: Ice particle interarrival times measured with a fast FSSP, J. Atmos. Ocean. Tech., 20, 249-261, https://doi.org/10.1175/15200426(2003)020<0249:IPITMW>2.0.CO;2, 2003.

Field, P. R., Heymsfield, A. J., and Bansemer, A.: Shattering and particle interarrival times measured by optical array probes in ice clouds, J. Atmos. Ocean. Tech., 23, 1357-1371, https://doi.org/10.1175/JTECH1922.1, 2006.

Finger, F., Werner, F., Klingebiel, M., Ehrlich, A., Jäkel, E., Voigt, M., Borrmann, S., Spichtinger, P., and Wendisch, M.: Spectral optical layer properties of cirrus from collocated airborne measurements and simulations, Atmos. Chem. Phys., 16, 76817693,https://doi.org/10.5194/acp-16-7681-2016, 2016.

Frey, W.: Airborne in situ measurements of ice particles in the tropical tropopause layer, $\mathrm{PhD}$ thesis, Johannes GutenbergUniversität, Mainz, available at: http://ubm.opus.hbz-nrw.de/ volltexte/2011/2924/ (last access: 8 September 2017), 2011.

Frey, W., Eichler, H., de Reus, M., Maser, R., Wendisch, M., and Borrmann, S.: A new airborne tandem platform for collocated measurements of microphysical cloud and radiation properties, Atmos. Meas. Tech., 2, 147-158, https://doi.org/10.5194/amt-2147-2009, 2009.

Gurk, Ch., Fischer, H., Hoor, P., Lawrence, M. G., Lelieveld, J., and Wernli, H.: Airborne in-situ measurements of vertical, seasonal and latitudinal distributions of carbon dioxide over Europe, Atmos. Chem. Phys., 8, 6395-6403, https://doi.org/10.5194/acp8-6395-2008, 2008

Hanjalić, K., Popovac, M., and Hadžiabdić, M.: A robust near-wall elliptic-relaxation eddy-viscosity turbulence model for CFD, Int. J. Heat Fluid Fl., 25, 1047-1051, https://doi.org/10.1016/j.ijheatfluidflow.2004.07.005, 2004.

Heymsfield, A. J.: Precipitation development in stratiform ice clouds: A microphysical and dynamical study, J. Atmos. Sci., 34, 367-381, https://doi.org/10.1175/15200469(1977)034<0367:PDISIC>2.0.CO;2, 1977.

Heymsfield, A. J. and Westbrook, C. D.: Advances in the estimation of ice particle fall speeds using laboratory and field measurements, J. Atmos. Sci., 67, 2469-2482, https://doi.org/10.1175/2010JAS3379.1, 2010.

IPCC: Climate Change 2013: The Physical Science Basis. Contribution of Working Group I to the Fifth Assessment Report of the Intergovernmental Panel on Climate Change, edited by: Stocker, 
T. F., Qin, D., Plattner, G.-K., Tignor, M., Allen, S. K., Boschung, J., Nauels, A., Xia, Y., Bex, V., and Midgley, P. M., Cambridge University Press, Cambridge, United Kingdom and New York, NY, USA, 1535 pp., 2013.

Jensen, E., Starr, J. D., and Toon, O. B.: Mission investigates tropical cirrus clouds, Eos T. Am. Geophys. Un., 85, 45-50, https://doi.org/10.1029/2004EO050002, 2004.

Jensen, E. J., Lawson, P., Baker, B., Pilson, B., Mo, Q., Heymsfield, A. J., Bansemer, A., Bui, T. P., McGill, M., Hlavka, D., Heymsfield, G., Platnick, S., Arnold, G. T., and Tanelli, S.: On the importance of small ice crystals in tropical anvil cirrus, Atmos. Chem. Phys., 9, 5519-5537, https://doi.org/10.5194/acp-95519-2009, 2009.

Kärcher and Lohmann, U.: A parameterization of cirrus cloud formation: Homogeneous freezing of supercooled aerosols, J. Geophys. Res., 107, 4010, https://doi.org/10.1029/2001JD000470, 2002.

Kienast-Sjögren, E., Spichtinger, P., and Gierens, K.: Formulation and test of an ice aggregation scheme for two-moment bulk microphysics schemes, Atmos. Chem. Phys., 13, 9021-9037, https://doi.org/10.5194/acp-13-9021-2013, 2013.

Klingebiel, M., de Lozar, A., Molleker, S., Weigel, R., Roth, A., Schmidt, L., Meyer, J., Ehrlich, A., Neuber, R., Wendisch, M., and Borrmann, S.: Arctic low-level boundary layer clouds: in situ measurements and simulations of mono- and bimodal supercooled droplet size distributions at the top layer of liquid phase clouds, Atmos. Chem. Phys., 15, 617-631, https://doi.org/10.5194/acp-15-617-2015, 2015.

Knollenberg, R. G.: Three New Instruments for Cloud Physics Measurements: The 2-D Spectrometer, the Forward Scattering Spectrometer Probe, and the Active Scattering Aerosol Spectrometer, Proc. Int. Conference on Cloud Physics, Boulder, CO, 26-30 July 1976.

Köllner, F.: Charakterisierung und Einsatz eines flugzeuggetragenen Ozonmessgerätes in der Grenzschicht, Diploma thesis, Institute for Physics of the Atmosphere, Johannes GutenbergUniversität, Mainz, Germany, 2013.

Koop, T., Luo, B. P., Tsias, A., and Peter, T.: Water activity as the determinant for homogeneous ice nucleation in aqueous solutions, Nature, 406, 611-614, https://doi.org/10.1038/35020537, 2000.

Korolev, A.: Reconstruction of the sizes of spherical particles from their shadow images. Part 1: Theoretical considerations, J. Atmos. Sci., 64, 3372-3375, https://doi.org/10.1175/JTECH1980.1, 2007a.

Korolev, A., McFarquhar, G., Lawson, P., Gayet, J. F., Krämer, M., Heymsfield, A., Rogers, D., Twohy, C., and Stetzer, O.: The effect of ice bouncing and shattering on the performance of airborne cloud microphysical instrumentation, AMS Conference Proceedings from Portland, Oregon, 2010.

Korolev, A., Emery, E., and Creelman, K.: Modification and tests of particle probe tips to mitigate effects of ice shattering, J. Atmos. Ocean. Techn., 30, 690-708, https://doi.org/10.1175/JTECH-D12-00142.1, 2013.

Lance, S., Brock, C. A., Rogers, D., and Gordon, J. A.: Water droplet calibration of the Cloud Droplet Probe (CDP) and in-flight performance in liquid, ice and mixed-phase clouds during ARCPAC, Atmos. Meas. Tech., 3, 1683-1706, https://doi.org/10.5194/amt-3-1683-2010, 2010.
Lynch, D. K.: Cirrus: History and Definition, Cirrus, Oxford University Press, Cambridge, New York, USA, 2002.

Molleker, S., Borrmann, S., Schlager, H., Luo, B., Frey, W., Klingebiel, M., Weigel, R., Ebert, M., Mitev, V., Matthey, R., Woiwode, W., Oelhaf, H., Dörnbrack, A., Stratmann, G., Grooß, J.U., Günther, G., Vogel, B., Müller, R., Krämer, M., Meyer, J., and Cairo, F.: Microphysical properties of synoptic-scale polar stratospheric clouds: in situ measurements of unexpectedly large $\mathrm{HNO}_{3}$-containing particles in the Arctic vortex, Atmos. Chem. Phys., 14, 10785-10801, https://doi.org/10.5194/acp-14-107852014, 2014.

Müller, S., Hoor, P., Berkes, F., Bozem, H., Klingebiel, M., Reutter, P., Smit, H., Wendisch, M., Spichtinger, P., and Borrmann, S.: In-situ detection of stratosphere-troposphere-exchange of cirrus particles in the mid-latitudes, Geophys. Res. Lett., 42, 949-955, https://doi.org/10.1002/2014GL062556, 2015.

Neis, P., Smit, H. G. J., Krämer, M., Spelten, N., and Petzold, A.: Evaluation of the MOZAIC Capacitive Hygrometer during the airborne field study CIRRUS-III, Atmos. Meas. Tech., 8, 12331243, https://doi.org/10.5194/amt-8-1233-2015, 2015.

Röschenthaler, T.: Aerodynamische Gestaltung der Schleppsonde AIRTOSS zur Untersuchung von Mehrphasenwolken mit Hilfe numerischer Strömungssimulationen, MS Thesis, Technische Universität Darmstadt, Darmstadt, Germany, 2013.

Sabburg, J. M. and Long, C. N.: Improved sky imaging for studies of enhanced UV irradiance, Atmos. Chem. Phys., 4, 2543-2552, https://doi.org/10.5194/acp-4-2543-2004, 2004.

Schlenczek, O., Fugal, J. P., Lloyd, G., Bower, K. N., Choularton, T. W., Flynn, M., Crosier, J., and Borrmann, S.: Microphysical properties of ice crystal precipitation and surface-generated ice crystals in a High Alpine environment in Switzerland, J. Appl. Meteorol. Clim., 56, 433-453, https://doi.org/10.1175/JAMC-D16-0060.1, 2016.

Siebert, H., Beals, M., Bethke, J., Bierwirth, E., Conrath, T., Dieckmann, K., Ditas, F., Ehrlich, A., Farrell, D., Hartmann, S., Izaguirre, M. A., Katzwinkel, J., Nuijens, L., Roberts, G., Schäfer, M., Shaw, R. A., Schmeissner, T., Serikov, I., Stevens, B., Stratmann, F., Wehner, B., Wendisch, M., Werner, F., and Wex, H.: The fine-scale structure of the trade wind cumuli over Barbados - an introduction to the CARRIBA project, Atmos. Chem. Phys., 13, 10061-10077, https://doi.org/10.5194/acp-13-100612013, 2013.

Thorsen, T. J., Fu, Q., and Comstock, J. M.: Cloud effects on radiative heating rate profiles over Darwin using ARM and Atrain radar/lidar observations, J. Geophys. Res., 118, 5637-5654, https://doi.org/10.1002/jgrd.50476, 2013.

Toon, O. B.: An overview of the tropical composition, AGU Fall Meeting Abstracts, 2007.

Weigel, R., Spichtinger, P., Mahnke, C., Klingebiel, M., Afchine, A., Petzold, A., Krämer, M., Costa, A., Molleker, S., Reutter, P., Szakáll, M., Port, M., Grulich, L., Jurkat, T., Minikin, A., and Borrmann, S.: Thermodynamic correction of particle concentrations measured by underwing probes on fast-flying aircraft, Atmos. Meas. Tech., 9, 5135-5162, https://doi.org/10.5194/amt-95135-2016, 2016.

Wendisch, M. and Yang, P.: Theory of Atmospheric Radiative Transfer, WILEY-VCH, 366 pp., 2012.

Wendisch, M., Keil, A., and Korolev, A. V.: FSSP characterization with monodisperse water droplets, J. Atmos. 
Ocean. Tech., 13, 1152-1165, https://doi.org/10.1175/15200426(1996)013<1152:FCWMWD>2.0.CO;2, 1996.

Wendisch, M., Müller, D., Schell, D., and Heintzenberg, J.: An airborne spectral albedometer with active horizontal stabilization, J. Atmos. Ocean. Tech., 18, 1856-1866, https://doi.org/10.1175/15200426(2001)018<1856:AASAWA>2.0.CO;2, 2001.

Wendisch, M., Pilewskie, P., Pommier, J., Howard, S., Yang, P., Heymsfield, A. J., Schmitt, C. G., Baumgardner, D., and Mayer, B.: Impact of cirrus crystal shape on solar spectral irradiance: A case study for subtropical cirrus, J. Geophys. Res., 110, D03202, https://doi.org/10.1029/2004JD005294, 2005.

Wendisch, M., Yang, P., and Pilewskie, P.: Effects of ice crystal habit on thermal infrared radiative properties and forcing of cirrus, J. Geophys. Res., 112, D08201, https://doi.org/10.1029/2006JD007899, 2007.
Werner, F., Ditas, F., Siebert, H., Simmel, M., Wehner, B., Pilewskie, P., Schmeissner, T., Shaw, R. A., Hartmann, S., Wex, H., Roberts, G. C., and Wendisch, M.: Twomey effect observed from collocated microphysical and remote sensing measurements over shallow cumulus, J. Geophys. Res., 119, 1534-1545, https://doi.org/10.1002/2013JD020131, 2014.

Zhang, Y., Macke, A., and Albers, F.: Effect of crystal size spectrum and crystal shape on stratiform cirrus radiative forcing, Atmos. Res., 52, 59-75, https://doi.org/10.1016/S0169-8095(99)00026$5,1999$.

Zöger, M., Afchine, A., Eicke, N., Gerhards, M. T., Klein, E., McKenna, D. S., Morschel, U., Schmidt, U., Tan, V., Tuitjer, F., Woyke, T., and Schiller, C.: Fast in situ stratospheric hygrometers: A new family of balloon-borne and airborne Lyman alpha photofragment fluorescence hygrometers, J. Geophys. Res., 104, 1807-1816, 1999. 